\title{
Anesthetic Consideration for Peroral Endoscopic Myotomy
}

\author{
Yun-Sic Bang and Chunghyun Park \\ Department of Anesthesiology and Pain Medicine, CHA Bundang Medical Center, CHA University, Seongnam, Korea
}

A recent achalasia guideline suggests that peroral endoscopic myotomy (POEM) is a safe option for achalasia that is as effective as Heller myotomy. It is recommended that POEM should be performed under general anesthesia. The incidence of adverse events such as bleeding, perforation, and carbon dioxide insufflation-related complications was lower in POEM under endotracheal general anesthesia than in POEM under sedation. Subcutaneous emphysema, pneumothorax, pneumomediastinum, pneumoperitoneum, and accompanying hemodynamic instability can be caused by carbon dioxide insufflation. Treatment of possible physiological changes and adverse events during the POEM procedure from the point of view of anesthesiologists may give endoscopists a new perspective on improving patient safety. The territory of therapeutic endoscopy can be expanded through cooperation with other departments, including anesthesia services. Efforts to understand different perspectives will certainly help not only secure patient safety but also expand the area of treatment. Clin Endosc 2019;52:549-555

Key Words: Complication; General endotracheal anesthesia; Peroral endoscopic myotomy

\section{INTRODUCTION}

Esophageal achalasia is a motility disorder of the lower esophageal or cardiac sphincter muscle due to incomplete relaxation. Conventional treatment options include medical treatments such as calcium-channel blockers and nitrates, ${ }^{1}$ balloon dilatation, and surgical myotomy using a laparoscopic approach (Heller myotomy).$^{2-4}$ Inoue et al. ${ }^{4}$ introduced peroral endoscopic myotomy (POEM) using carbon dioxide $\left(\mathrm{CO}_{2}\right)$ insufflation; thereafter, various studies have followed regarding technical modification, outcome, feasibility, efficacy, and safety. A recent achalasia guideline suggests that POEM is as effective as Heller myotomy. ${ }^{5,6}$ However, it is recommended that POEM should be performed under general anesthesia rather than under sedation to prevent unintentional patient

\section{Received: January 17, 2019 Revised: April 1, 2019}

Accepted: April 2, 2019

Correspondence: Chunghyun Park

Department of Anesthesiology and Pain Medicine, CHA Bundang Medical Center, CHA University, 59 Yatap-ro, Bundang-gu, Seongnam, Korea

Tel: +82-31-780-5157, Fax: +82-31-780-5157, E-mail: anesthpark@chamc.ac.kr ORCID: https://orcid.org/0000-0003-1916-6644

(c) This is an Open Access article distributed under the terms of the Creative Commons Attribution Non-Commercial License (http://creativecommons.org/ licenses/by-nc/3.0) which permits unrestricted non-commercial use, distribution, and reproduction in any medium, provided the original work is properly cited. movement and reduce mediastinal emphysema by achieving a positive intrathoracic pressure. ${ }^{7}$ Wang et al. reported that the incidence of adverse events (bleeding, perforation, and $\mathrm{CO}_{2}$ insufflation-related complications) was lower in POEM under endotracheal general anesthesia than in POEM intravenous sedation. ${ }^{8}$ Therefore, mutual cooperation and communication between anesthesiologists and endoscopists by improving the operator's understanding of general anesthesia is necessary. On the other hand, treatment of possible physiological changes and adverse events during the POEM procedure from the point of view of anesthesiologists may give endoscopists a new perspective on improving patient safety.

\section{PREOPERATIVE PATIENT ASSESSMENT}

Preoperative patient assessment is highly important. The risk of general anesthesia is assessed by integrating history taking, physical examination, and preoperative laboratory findings. Depending on the degree of risk, physical status is rated in accordance with the American Society of Anesthesiologists (ASA) classification (Table 1). ${ }^{9}$ This classification is an independent predictor of medical complications and mortality, and is used not only in the field of anesthesia for surgery 
but also in sedation performed outside the operating room. ${ }^{10}$ It could be needed in additional precise evaluations for patients with high ASA classification. Clinicians should obtain informed consent from patients about possible perioperative complications and risks associated with patients' underlying conditions.

\section{FASTING}

Fasting is essential before a general anesthesia because of the risk of aspiration pneumonia caused by reflux of gastric contents when positive pressure ventilation with a face mask is performed or the patient moves unintentionally and coughs. Preoperative fasting is usually $8 \mathrm{~h}$ in principle, but recently, it is recommended to allow $6 \mathrm{~h}$ for light meal and $2 \mathrm{~h}$ for clear liquid recently. ${ }^{11}$ However, no guideline exists for anesthesia management and pre-fasting time for POEM to date. In a recent case series on POEM anesthesia management, fasting times were reported to range from $8 \mathrm{~h}$ to $48 \mathrm{~h} .{ }^{12-15}$ Whether esophagogastroduodenoscopy (EGD) should be performed prophylactically to remove food that may remain in the esophagus is controversial. Prophylactic EGD was performed in two case series, ${ }^{12,15}$ but not in the other two series. ${ }^{13,14}$ One case series without prophylactic EGDs recognized the need for it, ${ }^{14}$ and the other claimed that prophylactic EGD itself was not necessary as it increased the patient's risk of aspiration. ${ }^{13}$ Further prospective studies on fasting time and prophylactic EGD for POEM will be needed in the future.

\section{PATIENT MONITORING}

Patient monitoring is based on standardized monitoring devices for noninvasive blood pressure, pulse oximetry, and electrocardiography (lead II) for general anesthesia. If the patient has cardiovascular or pulmonary disease, invasive arterial blood pressure monitoring and serial arterial blood gas analysis may be helpful. After endotracheal intubation is complete, capnography is monitored to view end-tidal $\mathrm{CO}_{2}$

Table 1. American Society of Anesthesiologists Classification System

\begin{tabular}{|c|c|c|}
\hline ASA PS Classification & Definition & Examples, including, but not limited to: \\
\hline ASA I & A normal healthy patient & Healthy, non-smoking, no or minimal alcohol use \\
\hline ASA II & A patient with mild systemic disease & $\begin{array}{l}\text { Mild diseases only without substantive functional limitations. Ex- } \\
\text { amples include (but not limited to): current smoker, social alco- } \\
\text { hol drinker, pregnancy, obesity }(30<\text { BMI }<40 \text { ), well-controlled } \\
\text { DM/HTN, mild lung disease }\end{array}$ \\
\hline ASA III & A patient with severe systemic disease & $\begin{array}{l}\text { Substantive functional limitations; One or more moderate to se- } \\
\text { vere diseases. Examples include (but not limited to): poorly con- } \\
\text { trolled DM or HTN, COPD, morbid obesity (BMI } \geq 40 \text { ), active } \\
\text { hepatitis, alcohol dependence or abuse, implanted pacemaker, } \\
\text { moderate reduction of ejection fraction, ESRD undergoing reg- } \\
\text { ularly scheduled dialysis, premature infant PCA }<60 \mathrm{wk} \text {, history } \\
\text { (>3 mo) of MI, CVA, TIA, or CAD/stents. }\end{array}$ \\
\hline ASA IV & $\begin{array}{l}\text { A patient with severe systemic disease } \\
\text { that is a constant threat to life }\end{array}$ & $\begin{array}{l}\text { Examples include (but not limited to): recent }(<3 \mathrm{mo}) \text { MI, CVA, } \\
\text { TIA, or CAD/stents, ongoing cardiac ischemia or severe valve } \\
\text { dysfunction, severe reduction of ejection fraction, sepsis, DIC, } \\
\text { ARD or ESRD not undergoing regularly scheduled dialysis }\end{array}$ \\
\hline ASA V & $\begin{array}{l}\text { A moribund patient who is not expected } \\
\text { to survive without the operation }\end{array}$ & $\begin{array}{l}\text { Examples include (but not limited to): ruptured abdominal/tho- } \\
\text { racic aneurysm, massive trauma, intracranial bleed with mass } \\
\text { effect, ischemic bowel in the face of significant cardiac pathology } \\
\text { or multiple organ/system dysfunction }\end{array}$ \\
\hline ASA VI & $\begin{array}{l}\text { A declared brain-dead patient whose } \\
\text { organs are being removed for donor } \\
\text { purposes }\end{array}$ & \\
\hline
\end{tabular}

The addition of "E" denotes Emergency surgery: an emergency is defined as existing when delay in treatment of the patient would lead to a significant increase in the threat to life or body part.

ARD, acute respiratory distress; ASA, American Society of Anesthesiologists; BMI, body mass index; CAD, coronary artery disease; COPD, chronic obstructive pulmonary disease; CVA, cerebrovascular accident; DIC, disseminated intravascular coagulation; DM, diabetes mellitus; ESRD, end-stage renal disease; HTN, hypertension; MI, myocardial infarction; PCA, post conceptual age; PS, physical status; TIA, transient ischemic attack. 
$\left(\right.$ etCO $\mathrm{C}_{2}$, which can be used to estimate arterial $\mathrm{CO}_{2}$ partial pressure $\left(\mathrm{PaCO}_{2}\right)$. For the POEM procedure, gas insufflation is essential for the formation of a submucosal tunnel and proper visualization. $\mathrm{CO}_{2}$ is the most commonly used gas because it is noncombustible, inexpensive, and colorless. In addition, it is believed to be safer than air because it is rapidly absorbed into the body and is excreted by the lungs and melts well in water, reducing the risk of embolism. ${ }^{16} \mathrm{PaCO}_{2}$ is usually 4 to $5 \mathrm{~mm}$ $\mathrm{Hg}$ higher than etCO $\mathrm{CO}_{2}$. The capnography should be closely monitored by anesthesiologists and increases in etCO $\mathrm{O}_{2}$ must be managed by appropriate increases in the minute ventilation to maintain etCO $\mathrm{C}_{2}$ under $45 \mathrm{~mm} \mathrm{Hg}$. ${ }^{13}$ Meanwhile, the peak inspiratory pressure (Pmax) must be closely observed during ventilator operation. POEM-related increase in Pmax can imply elevation of intra-abdominal pressure and serve as a clinical indicator of the need for percutaneous abdominal needle decompression (PND) during pneumoperitoneum. ${ }^{15}$

\section{INDUCTION OF ANESTHESIA}

The most important thing in the induction of anesthesia in patients with achalasia is the prevention of aspiration. In general, general anesthesia is known to induce aspiration at a rate of $3 / 10,000 .{ }^{16}$ However, in patients with achalasia, the probability of aspiration is higher than that in the general population, as the presence of food in the esophagus cannot be confirmed unless prophylactic EGD is performed. Therefore, in most cases, rapid sequence induction (RSI) is mandatory. RSI is used when fasting time is not known or not enough to minimize the risk of aspiration of gastric contents by using hypnotics and neuromuscular blocking agents with short onset time, with the assistant pressing the cricoid cartilage and minimizing or without positive pressure ventilation via face mask. A succinylcholine-depolarizing neuromuscular blocking agent is most suitable for RSI owing to its rapid onset of action. However, because it can cause many adverse effects, ${ }^{17}$ it is not an optimal choice. Instead, use of nondepolarizing neuromuscular blocking agents such as rocuronium, which has a relatively short effect onset time, is recommended. When rocuronium $1.2 \mathrm{mg} / \mathrm{kg}$ was used with propofol, no significant difference in intubation condition was found in comparison with succinylcholine. ${ }^{18}$ In addition, the types and doses of hypnotics, opioids, and inhalation anesthetics should be individually selected depending on the patient's underlying disease and hemodynamic status. After intubation, the endotracheal tube is fixed to the right side of the mouth to facilitate entry of the endoscope. The airway approach has two options, orotracheal and nasotracheal intubation. The benefits of orotracheal intubation are the large diameter, less airway bleed- ing, and easy suction of the respiratory tract. However, it can be moved along the endoscope in the oral cavity. By contrast, nasotracheal intubation is expected to be a relatively separate pathway to the larynx. The drawbacks of the nasotracheal tube are the smaller internal diameter than that of the orotracheal tube, easily causes nasal bleeding, and the curved tube, which makes suction difficult. Moreover, as the endoscopist usually stands next to the patient's head and perform surgery, accessibility to the airway may be difficult. Therefore, the proper depth and fixation of the endotrachaeal tube should be confirmed, and care should be taken to ensure that the eyes are properly protected. ${ }^{19}$ The abdomen is preferred to exposure to assist in detecting and treating pneumoperitoneum.

\section{POSSIBLE PHYSIOLOGICAL CHANGES IN POEM}

General anesthesia for POEM is followed by physiological changes according to the characteristics of the procedure. First, cardiovascular responses occur, including increased mean arterial pressure (MAP) and heart rate (HR). ${ }^{15}$ Löser et al. suggested that this should be understood in a context similar to the elevation of MAP and HR during laparoscopic surgery. ${ }^{15}$ The direct causes of absorbed $\mathrm{CO}_{2},{ }^{20}$ mechanical vascular compression, ${ }^{21}$ sympathetic stimulation, ${ }^{22}$ secretion of norepinephrine, ${ }^{23}$ and hemodynamic changes observed in POEM may be similar. Second, it might represent an impairment of the systemic $\mathrm{CO}_{2}$ balance and increases in Pmax. ${ }^{15}$ This is mostly due to endoscopic $\mathrm{CO}_{2}$ insufflation during POEM. As peritoneal absorption of $\mathrm{CO}_{2}$ during laparoscopic surgery, we suggest that subcutaneous, submucosal, and mediastinal $\mathrm{CO}_{2}$ absorption contribute to $\mathrm{CO}_{2}$ imbalance that induces respiratory acidosis. Increased Pmax implies elevated intra-abdominal pressure. It could be caused by gastric distension or pneumoperitoneum. It is treatable by suctioning of the stomach or PND. Anesthesiologists must continue monitoring these parameters carefully and ask endoscopists not to insufflate too much $\mathrm{CO}_{2}$ or to do suction of the stomach. Communication between anesthesiologists and endoscopists is important, and endoscopists need to understand the situation of the patients. Anesthesiologists try to maintain homeostasis and the adjust vital signs of patients by controlling the use of various anesthetics and drugs. However, POEM-related increase in Pmax and $\mathrm{PaCO}_{2}$ are difficult to control only by anesthesiologists. If communication between anesthesiologists and endoscopists is appropriate, the risk of procedure-related complications can be reduced. 


\section{POEM-RELATED ADVERSE EVENTS}

POEM is supposed to be related with various adverse events. Early adverse events are perioperative complications, including mucosal injury, esophageal perforation, major bleeding, subcutaneous emphysema, pneumothorax, pneumomediastinum, pneumoperitoneum, and pleural effusion. Late complications are related with patient outcomes such as symptomatic gastroesophageal reflux disease and esophagitis. ${ }^{24}$ Among them, anesthesiologists are concerned about perioperative adverse events especially related to $\mathrm{CO}_{2}$ insufflation because efforts may be necessary to detect and reduce their incidence.

\section{INSUFFLATION-RELATED ADVERSE EVENTS}

The most common adverse events associated with POEM are related to gas insufflation pneumomediastinum, pneumothorax, pneumoperitoneum, and subcutaneous emphysema because endoscopically insufflated gas may inadvertently track into surrounding tissues. The incidences of insufflation-related adverse events are quite variable, ranging from $7.5 \%$ to $55.5 \%$, according to studies. ${ }^{25-28}$ Pneumoperitoneum may cause inferior vena cava compression, preload reduction, and subsequent decreased cardiac output, especially in volume-depleted patients. These physiological changes are counterbalanced by sympathetic stimulation, causing tachycardia and systemic vasoconstriction. These alterations in physiological functions may put patients with compromised cardiopulmonary functions at risk

Two main factors reduce this complication, namely using $\mathrm{CO}_{2}$ instead of air and reducing the total volume of gas insufflation. ${ }^{7}$ As several research studies have established that air is absorbed 150 times slower than $\mathrm{CO}_{2}$ and $\mathrm{CO}_{2}$ insufflation is safe for endoscopic submucosal dissection, ${ }^{29-32}$ using $\mathrm{CO}_{2}$ is mandatory to decrease the volume of gas within the cavity or connective tissue space. Another crucial factor is to minimize the total amount of gas insufflated. Familiari et al. in a series of 100 patients who underwent POEM reported that low-flow $\mathrm{CO}_{2}$ tubing caused no events of tense pneumoperitoneum, whereas medium- or high-flow $\mathrm{CO}_{2}$ tubing resulted in tense pneumoperitoneum in $36.7 \%{ }^{33}$ Our institution applies low flow $\mathrm{CO}_{2}$ (approximately $1 \pm 0.3 \mathrm{~L} / \mathrm{min}$ ), which is considered appropriate to reduce complications associated with $\mathrm{CO}_{2}$ insufflation. Further study is needed to investigate the correlation between $\mathrm{CO}_{2}$ flow rate and the incidence of insufflation-related adverse events. Thus, this needs to be dealt with from an anesthesiologist's point of view.

\section{Hyperventilation}

General anesthesia with endotracheal intubation allows control of the minute ventilation volume. $\mathrm{CO}_{2}$ uptake caused by insufflation may be mitigated to some degree by hyperventilation. With anesthetic monitors showing etCO $\mathrm{CO}_{2}$ on screen, anesthesiologists can control tidal volume or respiratory rate, assuming $\mathrm{PaCO}_{2}$. However, once subcutaneous emphysema occurs, hyperventilation alone cannot maintain normocapnea because $\mathrm{CO}_{2}$ is continuously absorbed into circulation.

\section{Peak inspiratory pressure control}

During POEM, Pmax increases because of gastric distension or pneumoperitoneum. High Pmax can cause lung injury. ${ }^{34}$ It is helpful to expose the patient's abdomen to identify and treat pneumoperitoneum. ${ }^{15}$ To decrease Pmax, anesthesiologists usually reduce tidal volume and increase the respiratory rate to maintain minute ventilation. If Pmax continues to increase and the patient's abdomen is distended, the anesthesiologist can inform the endoscopists and ask for the necessary measure, including reducing $\mathrm{CO}_{2}$ insufflation, gastric suction, and PND. On the other hand, Inoue et al. insisted that positive pressure ventilation should be preferred at higher pressures than those generated by endoscopic $\mathrm{CO}_{2}$ insufflation to reduce mediastinal emphysema and the risk of embolization. ${ }^{4}$ There is disagreement over the limitation of Pmax during POEM up to now. Löser et al. ${ }^{15}$ reported the mean Pmax of patients needing PND was $22.8 \mathrm{cmH}_{2} \mathrm{O}$. They set the indication for PND at approximately 20\% from the baseline Pmax. Another study managed the patient's Pmax under $38 \mathrm{cmH}_{2} \mathrm{O}{ }^{13}$ Increasing Pmax to $>38 \mathrm{cmH}_{2} \mathrm{O}$ was managed by pulling back the endoscope from the tunnel and inserting it in the stomach lumen to suction excess $\mathrm{CO}_{2}$. If simultaneous increases in Pmax and etCO ${ }_{2}$ were observed, they treated it with PND. Taking the findings together, our opinion is that although the baseline Pmax may vary among patients depending on body mass index or underlying pulmonary disease, we consider it better to maintain Pmax at $<30 \mathrm{cmH}_{2} \mathrm{O}$.

\section{Subcutaneous needle drain}

Subcutaneous emphysema is most common among insufflation-related adverse events during POEM. As described earlier, detection of subcutaneous emphysema is important. Table 2 shows the recognizable changes that occurred with subcutaneous emphysema. ${ }^{35}$ Increased $\mathrm{CO}_{2}$ absorption can be somewhat managed by hyperventilation. However, subcutaneous needle drain at the area of the most severe subcutaneous emphysema would be needed..$^{36}$ After alcohol swab, the skin is punctured with a short 26-gauge needle. Then, the surrounding skin tissue with crepitus is squeezed manually. Although it can be helpful to drain the entrapped $\mathrm{CO}_{2}$ out- 
side, the ultimate solution is to end the procedure quickly.

\section{Percutaneous abdominal needle decompression}

Increased abdominal pressure is determined from clinical signs such as tympanic percussion sounds, distension of abdominal, subcutaneous emphysema, and increased Pmax. Increased abdominal pressure causes a negative effect on the pulmonary mechanics, decreased venous return to the heart, and decreased visceral organ perfusion. As PND is an invasive procedure, communication and consensus between the endoscopist and the anesthesiologist are mandatory. For PND, a 14- or 16-gauge angiocatheter cannula is inserted under sterile conditions at the point of the right upper abdominal quadrant at least $5 \mathrm{~cm}$ below the rib cage after confirming that the lower edge of the liver could not be palpated (Fig. 1). ${ }^{15}$ According to the author's opinion, to secure safety, ultrasonography-guided needle puncture would be a good choice.

POEM-related adverse events, especially focusing insufflation-related adverse events, have been discussed. Although these are usually well managed without clinical morbidity, patient's pain and increased cost due to treatment of adverse events must be reduced. Thus, detection of the preceding signs of perioperative adverse events and prevention with close communication and cooperation are valuable.

\section{POSTOPERATIVE PAIN CONTROL}

Postoperative pain is one of the most undesirable experiences after surgery. Not only subjective pain itself but also side effects related to postoperative pain such as cardiovascular effects, respiratory depression, urinary and digestive dysfunction, and neuroendocrine dysfunction are a major concern for anesthesiologists. ${ }^{37}$ Postoperative pain control is essential for POEM because it results in a considerable amount of postoperative pain. Patient-controlled analgesia (PCA) with an opioid can satisfy the different ranges of analgesia required

Table 2. Recognizable Changes Seen with Subcutaneous Emphysema

Crepitus

Insufflation problems (flow and pressure)

Hypercarbia (monitor end-tidal $\mathrm{CO}_{2}$ )

Acidosis (monitor partial pressure of $\mathrm{CO}_{2}$ in arterial blood and rule out malignant hyperthermia)

Changes in lung compliance

Cardiac arrhythmias, sinus tachycardia, and hypertension

Intraoperative increase in partial pressure of end-tidal $\mathrm{CO}_{2}>50$ $\mathrm{mm} \mathrm{Hg}$

$\mathrm{CO}_{2}$, carbon dioxide. for individual patients. ${ }^{38}$ Opioids are widely used for PCA owing to their excellent analgesic effect; however, they can cause adverse events such as nausea, vomiting, pruritus, and respiratory depression. ${ }^{39}$ Combining adjunctive medications, including non-steroidal anti-inflammatory drugs, ketamine, and anti-emetics, has been used to minimize opioid-related side effects. ${ }^{40,41}$ A recent study showed that administration of dexmedetomidine with opioid-based postoperative PCA can exert a high analgesic effect and reduce opioid consumption and related adverse events. ${ }^{42}$

\section{POSTOPERATIVE NAUSEA AND VOMITING}

General anesthesia itself or opioid use for postoperative pain control can cause postoperative nausea and vomiting (PONV). PONV occurring immediately after the POEM procedure can cause bleeding and, in severe cases, damage to the surgical site. Various factors such as patient characteristics, anesthesia methods, surgical procedure, and postoperative care contribute to the increase in the incidence of PONV. ${ }^{43}$ Female sex, non-smoking, a history of fast-motion sickness, and the use of postoperative opioids are known as risk factors of PONV. From a preventive point of view, propofol is well known to have an antiemetic effect. Therefore, total intrave-

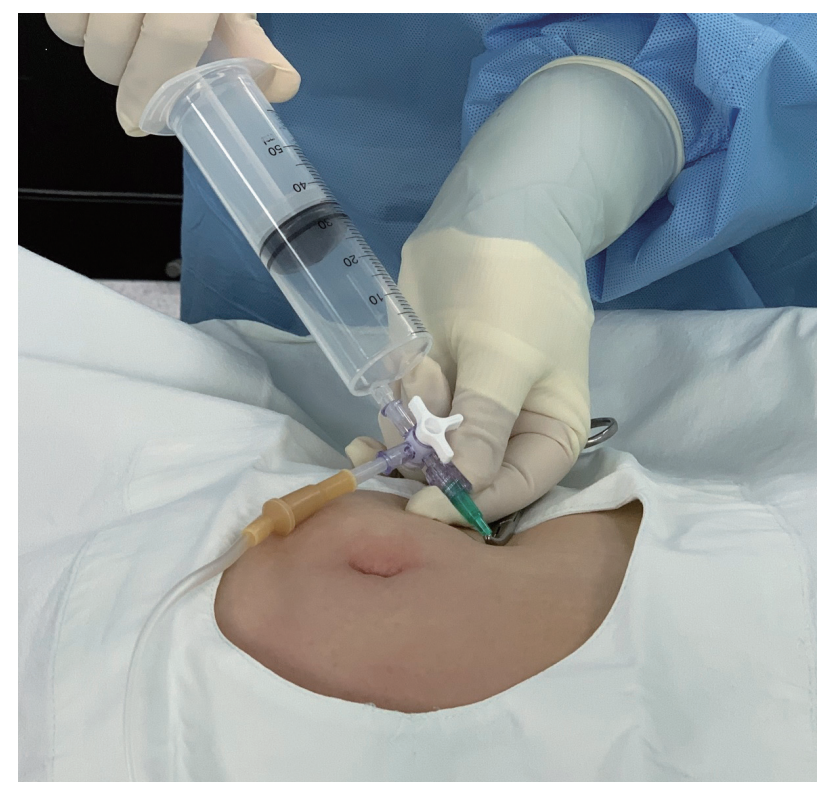

Fig. 1. Percutaneous abdominal needle decompression. An 18-gauge angiocatheter cannula is inserted under sterile conditions at the point of right upper abdominal quadrant at least $5 \mathrm{~cm}$ below the rib cage after confirming that the lower edge of the liver could not be palpated. Gas in the abdominal cavity can be discharged by either syringe with negative pressure or natural drain through a fluid line using a three-way stopcock. 
nous anesthesia using propofol has been reported to be an effective method for reducing the incidence of PONV. ${ }^{44}$ In a therapeutic approach, serotonin (5-hydroxytryptamine, subtype $\left.3\left[5-\mathrm{HT}_{3}\right]\right)$ receptor antagonists have been most widely used because of its minimal side effects. First-generation (ondansetron, granisetron, ramosetron, and tropisetron) and second-generation (palonosetron) $5-\mathrm{HT}_{3}$ receptor antagonists are available. ${ }^{45}$ If the patient is at risk of PONV, the $5-\mathrm{HT}_{3}$ antagonists are considered the first drugs of choice. Other drugs such as metoclopropamide and dexamethasone can also be used as preventive or therapeutic drugs. ${ }^{46}$

\section{FUTURE OF ANESTHETIC MANAGEMENT FOR POEM}

Currently, efforts are being made to provide anesthesia services in the endoscopic unit. Aside from sedation for EGD, general anesthesia is also being offered in the endoscopic unit by a dedicated team of anesthesiologists with extensive experience in gastrointestinal endoscopy. ${ }^{47}$ Yang et al. ${ }^{13}$ supported the feasibility of POEM performed by an endoscopist in the endoscopic unit. The major advantage of performing POEM in an endoscopic unit is that endoscopists can perform it in a familiar environment with no hassle of endoscopic equipment movement. However, some conditions must be met. Pannu et al. ${ }^{48}$ suggested that preparation of the following before performing POEM in an endoscopic unit is essential: (1) stateof-the-art facilities, (2) general anesthesia equipment in the endoscopy unit, (3) full anesthesia support team with protocol of anesthesia for POEM, (4) Considering surgical back-up.

On the other hand, no anesthetic guidelines have been established for POEM and anesthetic management is inadequate. Appropriate fasting guidelines, precautions during induction, and consensus about treating insufflation-related adverse events should be studied.

\section{CONCLUSIONS}

POEM is an effective and safe treatment option for achalasia. It is representative of a new era in which the territory of therapeutic endoscopy can be expanded through cooperation with other departments, including anesthesia services. Efforts to understand different perspectives will certainly help not only secure patient safety but also expand the area of treatment.

Conflicts of Interest

The authors have no financial conflicts of interest.

\section{REFERENCES}

1. Ahmed A. Achalasia: what is the best treatment? Ann Afr Med 2008; 7:141-148

2. Boeckxstaens GE, Zaninotto G, Richter JE. Achalasia. Lancet 2014;383:83-93.

3. Campos GM, Vittinghoff E, Rabl C, et al. Endoscopic and surgical treatments for achalasia: a systematic review and meta-analysis. Ann Surg 2009;249:45-57.

4. Inoue $\mathrm{H}$, Minami $\mathrm{H}$, Kobayashi $\mathrm{Y}$, et al. Peroral endoscopic myotomy (POEM) for esophageal achalasia. Endoscopy 2010;42:265-271.

5. Pandolfino JE, Gawron AJ. Achalasia: a systematic review. JAMA 2015;313:1841-1852.

6. Zaninotto G, Bennett C, Boeckxstaens G, et al. The 2018 ISDE achalasia guidelines. Dis Esophagus 2018;31(9).

7. Bechara R, Ikeda H, Inoue H. Peroral endoscopic myotomy: an evolving treatment for achalasia. Nat Rev Gastroenterol Hepatol 2015;12:410-426.

8. Wang J, Tan N, Xiao Y, et al. Safety and efficacy of the modified peroral endoscopic myotomy with shorter myotomy for achalasia patients: a prospective study. Dis Esophagus 2015;28:720-727.

9. Hurwitz EE, Simon M, Vinta SR, et al. Adding examples to the ASA-physical status classification improves correct assignment to patients. Anesthesiology 2017;126:614-622.

10. Hackett NJ, De Oliveira GS, Jain UK, Kim JY. ASA class is a reliable independent predictor of medical complications and mortality following surgery. Int J Surg 2015;18:184-190.

11. Practice guidelines for preoperative fasting and the use of pharmacologic agents to reduce the risk of pulmonary aspiration: application to healthy patients undergoing elective procedures: an updated report by the American Society of Anesthesiologists Task Force on preoperative fasting and the use of pharmacologic agents to reduce the risk of pulmonary aspiration. Anesthesiology 2017;126:376-393.

12. Tanaka E, Murata H, Minami H, Sumikawa K. Anesthetic management of peroral endoscopic myotomy for esophageal achalasia: a retrospective case series. J Anesth 2014;28:456-459.

13. Yang D, Pannu D, Zhang Q, White JD, Draganov PV. Evaluation of anesthesia management, feasibility and efficacy of peroral endoscopic myotomy (POEM) for achalasia performed in the endoscopy unit. Endosc Int Open 2015;3:E289-E295.

14. Goudra B, Singh PM, Gouda G, Sinha AC. Peroral endoscopic myotomy-initial experience with anesthetic management of 24 procedures and systematic review. Anesth Essays Res 2016;10:297-300.

15. Löser B, Werner YB, Punke MA, et al. Anesthetic considerations for patients with esophageal achalasia undergoing peroral endoscopic myotomy: a retrospective case series review. Can J Anaesth 2017;64:480-488.

16. Abdulla S. Pulmonary aspiration in perioperative medicine. Acta Anaesthesiol Belg 2013;64:1-13.

17. Orebaugh SL. Succinylcholine: adverse effects and alternatives in emergency medicine. Am J Emerg Med 1999;17:715-721.

18. Tran DT, Newton EK, Mount VA, Lee JS, Wells GA, Perry JJ. Rocuronium versus succinylcholine for rapid sequence induction intubation. Cochrane Database Syst Rev 2015;(10):CD002788.

19. Lee JH, Chung CJ, Lee SC, Shin HJ. Anesthetic management of transoral natural orifice transluminal endoscopic surgery: two cases report. Korean J Anesthesiol 2014;67:148-152.

20. Ho HS, Saunders CJ, Gunther RA, Wolfe BM. Effector of hemodynamics during laparoscopy: $\mathrm{CO}_{2}$ absorption or intra-abdominal pressure? J Surg Res 1995;59:497-503.

21. Hirvonen EA, Poikolainen EO, Pääkkönen ME, Nuutinen LS. The adverse hemodynamic effects of anesthesia, head-up tilt, and carbon dioxide pneumoperitoneum during laparoscopic cholecystectomy. Surg Endosc 2000;14:272-277.

22. Koivusalo AM, Kellokumpu I, Scheinin M, Tikkanen I, Mäkisalo H, Lindgren L. A comparison of gasless mechanical and conventional car- 
bon dioxide pneumoperitoneum methods for laparoscopic cholecystectomy. Anesth Analg 1998;86:153-158.

23. Myre K, Rostrup M, Buanes T, Stokland O. Plasma catecholamines and haemodynamic changes during pneumoperitoneum. Acta Anaesthesiol Scand 1998;42:343-347.

24. Cho YK, Kim SH. Current status of peroral endoscopic myotomy. Clin Endosc 2018;51:13-18.

25. Akintoye E, Kumar N, Obaitan I, Alayo QA, Thompson CC. Peroral endoscopic myotomy: a meta-analysis. Endoscopy 2016;48:1059-1068.

26. Ren Z, Zhong Y, Zhou P, et al. Perioperative management and treatment for complications during and after peroral endoscopic myotomy (POEM) for esophageal achalasia (EA) (data from 119 cases). Surg Endosc 2012;26:3267-3272.

27. Jayan N, Jacob JS, Mathew M, Mukkada RJ. Anesthesia for peroral endoscopic myotomy: a retrospective case series. J Anaesthesiol Clin Pharmacol 2016;32:379-381.

28. Talukdar R, Inoue H, Nageshwar Reddy D. Efficacy of peroral endoscopic myotomy (POEM) in the treatment of achalasia: a systematic review and meta-analysis. Surg Endosc 2015;29:3030-3046.

29. Maeda Y, Hirasawa D, Fujita N, et al. A pilot study to assess mediastinal emphysema after esophageal endoscopic submucosal dissection with carbon dioxide insufflation. Endoscopy 2012;44:565-571.

30. Maeda Y, Hirasawa D, Fujita N, et al. A prospective, randomized, double-blind, controlled trial on the efficacy of carbon dioxide insufflation in gastric endoscopic submucosal dissection. Endoscopy 2013;45:335341.

31. Saito Y, Uraoka T, Matsuda T, et al. A pilot study to assess the safety and efficacy of carbon dioxide insufflation during colorectal endoscopic submucosal dissection with the patient under conscious sedation. Gastrointest Endosc 2007;65:537-542.

32. Cai MY, Zhou PH, Yao LQ, Zhu BQ, Liang L, Li QL. Thoracic CT after peroral endoscopic myotomy for the treatment of achalasia. Gastrointest Endosc 2014;80:1046-1055.

33. Familiari P, Gigante G, Marchese M, et al. Peroral endoscopic myotomy for esophageal achalasia: outcomes of the first 100 patients with shortterm follow-up. Ann Surg 2016;263:82-87.

34. Rich PB, Reickert CA, Sawada S, et al. Effect of rate and inspiratory flow on ventilator-induced lung injury. J Trauma 2000;49:903-911.

35. Ott DE. Subcutaneous emphysema--beyond the pneumoperitoneum. JSLS 2014;18:1-7.
36. Coronil ÁB, Sanchez-Cañete AM, Bartakke AA, Fernández JG, García AI. Life-threatening subcutaneous emphysema due to laparoscopy. Indian J Anaesth 2016;60:286-288.

37. Hopf HW, Weitz S. Postoperative pain management. Arch Surg 1994;129:128-132.

38. Song SO, Jee DL, Koo BU. Analysis of 1,590 patients of IV-PCA for postoperative pain management. J Korean Pain Soc 1996;9:354-362.

39. Dahan A, Aarts L, Smith TW. Incidence, reversal, and prevention of opioid-induced respiratory depression. Anesthesiology 2010;112:226238.

40. Lin TF, Yeh YC, Yen YH, Wang YP, Lin CJ, Sun WZ. Antiemetic and analgesic-sparing effects of diphenhydramine added to morphine intravenous patient-controlled analgesia. $\mathrm{Br} J$ Anaesth 2005;94:835-839.

41. Michelet P, Guervilly C, Hélaine A, et al. Adding ketamine to morphine for patient-controlled analgesia after thoracic surgery: influence on morphine consumption, respiratory function, and nocturnal desaturation. Br J Anaesth 2007;99:396-403.

42. Kweon DE, Koo Y, Lee S, Chung K, Ahn S, Park C. Postoperative infusion of a low dose of dexmedetomidine reduces intravenous consumption of sufentanil in patient-controlled analgesia. Korean J Anesthesiol 2018; $71: 226-231$.

43. Golembiewski J, Chernin E, Chopra T. Prevention and treatment of postoperative nausea and vomiting. Am J Health Syst Pharm 2005;62:1247-1260; quiz 1261-1262.

44. Sneyd JR, Carr A, Byrom WD, Bilski AJ. A meta-analysis of nausea and vomiting following maintenance of anaesthesia with propofol or inhalational agents. Eur J Anaesthesiol 1998;15:433-445.

45. Kovac AL. Comparative pharmacology and guide to the use of the serotonin 5-HT3 receptor antagonists for postoperative nausea and vomiting. Drugs 2016;76:1719-1735.

46. Gan TJ, Diemunsch P, Habib AS, et al. Consensus guidelines for the management of postoperative nausea and vomiting. Anesth Analg 2014;118:85-113.

47. Kim GE, Kim DK, Choi JW, Chung IS, Jung DW. The safety of endoscopic esophageal procedures under general anesthesia. Korean J Anesthesiol 2017;70:555-560.

48. Pannu D, White JD, Draganov PV. Peroral endoscopic myotomy in the endoscopy unit: location, location, location. Gastrointest Endosc 2016;83:126-128. 